\title{
The modified application of Perron's theorem to evolutionary and palaeoecological studies of invertebrates in palaeobiology
}

\author{
Richard Arthur Reyment
}

\begin{abstract}
Oskar Perron's theorem states that among the latent roots and vectors of a real positive symmetric matrix $\mathbf{A}$ there will be a real positive value, to wit the maximum root, which has a positive latent vector (i.e., all components of which are positive, $\mathbf{x}>0$ ) and which is not surpassed by any other latent root of the matrix. In a size-shape-time study of a fossil invertebrate species there is a tensorial element involved which operates at different rates in different directions and at typical locations in a tissue. Whenever it is not composed of a vector of ones, the first latent vector includes an expression of shape-variation. Unequal loadings represent different rates of extension in relation to general size. Hence, for a vector with unequal positively signed components, the greater the increase in size, the more will the proportions between the elements diverge. Data on fossil foraminifers and ostracods are used to exemplify the significance of Perron's theorem.
\end{abstract}

Richard Arthur Reyment. Fellow of the Royal Swedish Academy of Sciences, Emeritus Professor of Geology at the University of Uppsala, Sweden

Keywords: Perron's theorem, invertebrates, shape-variation, palaeobiology

\section{PERRON'S THEOREM}

The Oskar Perron theorem states that among the latent roots of a real positive symmetric matrix A there will be a real positive value, $\lambda=\mathbf{x}$, the maximum root, the value of which is not surpassed by any other latent root of the matrix and which has a positive latent vector $\mathbf{x}>0$.

Perron's theorem (1907) and its amplification by Frobenius (1912) are not unknown to various fields of physics, engineering and even social sciences. However, biological applications, especially palaeobiological analyses, require the use of a specific, rigid computational procedure, which is more elaborate than is encountered in the usual case.

Bookstein (1991, section 4:3) raised several important points concerning the size-shape concept for organisms in a biological geometrical setting. He pointed out that growth and shape changes over time encompass a tensorial component. These factors operate at different rates at different directions and at typical locations in a tissue. Bookstein (1991) also noted that the commonly made analysis of size in relation to shape presup- 
poses that the variation in shape is subordinate to variation in size.

Whenever it is not composed of a vector of ones, the first latent vector includes an expression of shape-variation. Unequal loadings represent different rates of extension. Hence, for a vector with unequal positively signed elements the greater the increase in size, the more will the proportions between the components of the vector diverge. Aspects of the problems involved are taken up in Bookstein (1991) and Reyment and Bookstein (1993).

\section{AN EXAMPLE OF SIZE AND SHAPE CONFOUNDING}

Using data on a time-series for the Miocene foraminifer Brizalina mandoroveensis we can illustrate how size and shape may be inextricably joined. The data consist of stratigraphically well separated sampling points observed on cored borehole material from the Miocene at lkang of Cameroun (West Africa). Details of the material studied are available in Bookstein (1991) and Reyment (1987).

The four distance measures observed here are: 1 . breadth of the test; 2 . diameter of the last chamber; 3 . diameter of the penultimate chamber; and 4 . diameter of the proloculus.

The chronologically ordered values computed for the same borehole sequence and displayed in Table 1 and Table 2 differ. They indicate that there is a differentiation in the size-shape status of the

TABLE 1. The latent roots and vectors of the stratigraphically lower (i.e., older, $1810 \mathrm{~m}$ ) sample of Brizalina.

\begin{tabular}{|c|c|c|c|}
\hline \multicolumn{5}{|l|}{ Percentages of the latent roots } \\
\hline $\mathbf{1}$ & $\mathbf{2}$ & $\mathbf{3}$ & $\mathbf{4}$ \\
\hline 59.127 & 37.825 & 2.051 & 0.997 \\
\hline \multicolumn{5}{|l}{} \\
\hline $\mathbf{1}$ & $\mathbf{2}$ & $\mathbf{3}$ & $\mathbf{4}$ \\
\hline 0.628 & 0.000 & 0.499 & 0.598 \\
\hline 0.182 & 0.738 & -0.580 & 0.293 \\
\hline 0.096 & 0.623 & 0.544 & -0.554 \\
\hline 0.751 & -0.259 & -0.345 & -0.500 \\
\hline
\end{tabular}

first latent vector such that any increase in size would be accompanied by a change in shape unless all of the components of the latent vector were ones (Reyment and Bookstein, 1993). The information conveyed by Tables 1 and 2 indicates that there has been a marked shift in the geometry of the test of Brizalina over the sampled interval inasmuch as the angle between the first two vectors is large. A reasonable interpretation of this shift is that it could be due to palaeoecological factors. The measurements underlying the Brizalina example are listed in Bookstein (1991,table A.4.4).

\section{PERRON'S THEOREM IN THE GENERAL CASE}

It might be thought that some kind of a transformation could be invoked for circumventing the constraint resident in Perron's theorem. Example include correlations between variables and taking of logarithms. A worked example, summarized in Table 3, taken from Reyment and Bookstein (1993), serves to illustrate this point.

The five distance measures used were: 1. maximum length of the shell; 2 . distance from the eye-tubercle to the ventral margin; 3 . posterior curvature of the carapace; 4. posterior distance from the dorsal margin to the ventral margin; and 5 . length of the ventral rib.

Exactly as predicted by Perron's theorem the vector components associated with the largest latent root are all positive in sign (N.B. the vector components are to be read horizontally across the page). The components of the subsequent latent

TABLE 2. The latent roots and vectors of the stratigraphically younger core-sample of Brizalina (i.e., $1718 \mathrm{~m}$ )

\begin{tabular}{|c|c|c|c|}
\hline \multicolumn{5}{|l|}{ Percentages of the latent roots } \\
\hline $\mathbf{1}$ & $\mathbf{2}$ & $\mathbf{3}$ & $\mathbf{4}$ \\
\hline 61.441 & 29.275 & 6.181 & 3.102 \\
\hline \multicolumn{5}{|l|}{} \\
\hline $\mathbf{1}$ & $\mathbf{2}$ & $\mathbf{3}$ & $\mathbf{4}$ \\
\hline 0.387 & 0.651 & 0.139 & -0.638 \\
\hline 0.367 & -0.134 & 0.878 & 0.276 \\
\hline 0.764 & -0.521 & -0.353 & -0.145 \\
\hline 0.365 & 0.535 & -0.291 & 0.704 \\
\hline
\end{tabular}


TABLE 3. Latent roots and vectors for five taxonomic distance traits $(\mathrm{N}=18)$ for the species of ostracods Neobuntonia airella, Oligocene, Bells Headland, Victoria, Australia ( McKenzie et al., 1991).

\begin{tabular}{|c|c|c|c|c|c|c|}
\hline \multicolumn{2}{|c|}{ Latent roots } & \multicolumn{5}{c|}{ Latent vectors by rows } \\
\hline Root No. & Percent & $\mathbf{1}$ & $\mathbf{2}$ & $\mathbf{3}$ & $\mathbf{4}$ & $\mathbf{5}$ \\
\hline 1. & $0.01306(81.48 \%)$ & 0.1627 & 0.2506 & 0.9270 & 0.1609 & 0.1596 \\
\hline 2. & $0.00244(15.20 \%)$ & 0.4782 & 0.5868 & -0.3690 & 0.4752 & 0.2549 \\
\hline 3. & $0.00031(1.94 \%)$ & 0.0558 & -0.6911 & 0.0012 & 0.5456 & 0.4708 \\
\hline 4. & $0.00015(0.95 \%)$ & 0.0480 & 0.0677 & -0.0585 & -0.6022 & 0.7919 \\
\hline 5. & $0.00007(0.43 \%)$ & -0.8600 & 0.3327 & -0.0330 & 0.2965 & 0.2467 \\
\hline
\end{tabular}

vectors are either negative or positive in sign, and orthogonal, but not entirely the one nor the other, a natural outcome of the Perron-type matrix.

The example given in Table 3 makes it clear that any arbitrary interpretation of latent roots and vectors based on a Perronian matrix cannot be valid for a meaningful study of growth and shape in biological work, such as is implied in the use of "Principal Components." The PCA reification of 0 Jolicoeur and Mosimann (1960) is based on the suggestion that if the coefficients of the first principal component are positive, then it can be interpreted as a measure of size. The subsequent principal components will house positive and negative components that can be taken to be measures of shape. Mardia et al. (1979) pointed out that for a covariance matrix with positive elements, Perron's theorem ensures that all the coefficients of the principal component are positive. They also underscored (Mardia et al., 1979, p. 241) that the arbitrary behaviour of PC loadings is not consistent with a scientifically acceptable concept of size and shape, referring to Rao (1964). Reyment and Jöreskog (1993, section 2.11) consider further aspects of the Principal Component concept including geometric properties of latent roots and vectors.

\section{VARIATION IN THE FIRST LATENT VECTOR IN RELATION TO TIME}

In this section time-correlated change in the Perronian components of the first latent vector over the sampled range of the Ikang borehole (Cameroun) sequence provides an insight into palaeoecological change over time. The comparison is displayed in Table 4.
There is a sharply marked contrast between the structure of the first latent vector for the stratigraphically youngest data listed in Table 4, although all four core samples obtained from the older levels do not deviate substantially from each other. This result is of special interest and could possibly be the result of an ecological shift.

\section{CONCLUSIONS AND A SET OF RULES}

1. The appropriate procedure for analysing taxonomically relevant "distance" data that conform with the Peronian solution requires that the variables be homogeneous - they must bear a natural morphological relationship to each other.

TABLE 4. The "Peronian" components of the first latent vector for Brizalina for sampling levels of the Ikang borehole cores.

\begin{tabular}{|c|c|c|c|c|}
\hline $\begin{array}{c}\text { Depth of } \\
\text { Sample }\end{array}$ & \multicolumn{4}{|c|}{ Components of the first latent vector } \\
\hline $\begin{array}{c}\text { (in } \\
\text { metres) }\end{array}$ & 1 & 2 & 3 & 4 \\
\hline 1718 & 0.387 & 0.367 & 0.764 & 0.365 \\
\hline 1740 & 0.621 & 0.146 & 0.200 & 0.744 \\
\hline 1763 & 0.621 & 0.383 & 0.307 & 0.611 \\
\hline 1787 & 0.558 & 0.456 & 0.284 & 0.633 \\
\hline 1810 & 0.628 & 0.182 & 0.096 & 0.751 \\
\hline
\end{tabular}


2. The reference points must possess taxonomic significance

3. Interpreting the first latent vector as an expression of size, such is done in principal components, is fallacious. This point is obvious from the work of Bookstein (1991).

4. What you cannot do! A caveat.

The Peronian approach cannot be applied to spirally coiled shells (cf. Klein, 1926). An analysis of variability in spirally coiled shells requires expertise in the field of classical Solid Geometry.

\section{REFERENCES}

Bookstein, F.L. 1991. Morphometric tools for landmark data: geometry and biology. Cambridge University Press, U. K.

Frobenius, G. 1912. Über Matrizen aus nicht-negativen Elementen. Sitzungsberichte der königlichen Preussischen Akademie der Wissenschaften (1912):456477.

Jolicoeur, P. and Mosimann, J. E. 1960. Size and shape variation in the painted turtle. Growth, 24:335-350.
Klein, O. 1926. Vorlesungen über höhere Geometrie (Nachdruck 1968). Julius Springer Verlag, Berlin.

Mardia, K.V., Kent, J.T., Bibby, J.M. 1979. Multivariate Analysis. Academic Press, U. K.

McKenzie, K.G., Reyment, R.A., Reyment, E.R. 1991. Eocene-Oligocene Ostracoda from South Australia and Victoria, Australia. Revista Española de Paleontologia, 6(2):125-175.

Perron, O. 1907. Zur Theorie der Matrizen. Mathematische Annalen, 64:248-263.

Rao, C.R. 1964. The use and interpretation of principal component analysis in applied research. Sankhya $A$ 26:329-358.

Reyment, R.A. 1987. Ornamental polymorphism and morphological integration in Brizalina mandoroveenensis (Miocene,Cameroun). Journal of African Earth Sciences, 6:293-299.

Reyment, R.A. and Bookstein, F.L. 1993 . Infraspecific variability in shape in Neobuntonia airella: an exposition of geometric morphometry, p. 291-314. In McKenzie K.G. and Jones P.J. (ed.), Ostracoda in the Earth and Life Sciences, Proceedings of the $11^{\text {th }}$ International Symposium on Ostracoda (1991), Balkema, Rotterdam, Brookfeld.

Reyment, R.A. and Jöreskog, K.G. 1993. Applied factor analysis in the natural sciences. Cambridge University Press, U. K. 